\title{
A LITERATURA DO SÉCULO XIX E SEUS DESDOBRAMENTOS NO ENSINO DE LÍNGUA PORTUGUESA NA ATUALIDADE COM VISTAS AO PRECONCEITO LINGUÍSTICO
}

Livia Marinho Lessa Barboza (UERJ)

liviamarinho_vida@hotmail.com

A língua é ou faz parte do aparelho ideológico, comunicativo e estético da sociedade que a própria língua define e individualiza. (Leonor Buescu)

\section{Introdução}

É interessante notar que os estudos linguísticos no Brasil avançaram a partir da década de 1960 estigmatizando o ensino da gramática na escola, esquecendo-se de que a adequação entre a norma padrão e o registro informal são de obrigação regulatória do professor.

Não se trata de estereotipar a gramática negligenciando-a como se nenhuma importância tivesse. Trata-se antes de prover a alunos e professores mecanismos modernos que desenvolvam a competência gramatical, aumentando, inclusive, a competência discursiva do alunado a partir de seu próprio conhecimento intrínseco e internalizado ao longo de sua vivência.

A literatura brasileira contribuiu para a "polarização sociolinguística" (MATTOS E SILVA, 2002) aumentando, ainda que despretensiosamente, o abismo existente entre o português oral e o escrito.

Isso porque as gramáticas prescritivas se valem de exemplos retirados das literaturas escritas para uma minoria branca e escolarizada, conforme salienta Mattos e Silva (2002).

A sócio-história do Brasil informa também que, até os fins do século XVIII, o número de letrados não ultrapassaria 0,5\% da população (Houaiss 1985: 137). Só ao longo do século XIX e inícios do XX é que essa precarieda- 


\section{FACULDADE DE FORMAÇÃO dE PROFESSORES}

de do letramento e escolarização no Brasil passa a um patamar de $20 \%$ a $30 \%$ de indivíduos escolarizados, segundo o mesmo autor. (MATTOS E SILVA, 2002)

Ora, para quem escrevia então os literatos de três séculos atrás? Não seria para uma minoria abastarda cuja escola propiciava ensino homogeneizado e de maior densidade que o proporcionado hoje ao falante de LP no Brasil?

Então como conviver com realidades sócio-históricas tão distantes dentro do mesmo universo de ensino da LP nos dias atuais?

É inegável que já exista hoje livros didáticos que já se utilizem de registros menos formais para o ensino de LP, contudo, ainda é o padrão formal, prescritivo, das gramáticas normativas que é cobrado em concursos públicos, vestibulares etc.

O professor Bagno (2006) salienta que:

Uma das principais tarefas do professor de língua é conscientizar seu aluno de que a língua é como um grande guarda-roupa, onde é possível encontrar todo tipo de vestimenta. (BAGNO, 2006)

O preconceito quanto ao falar é castrador e mesmo assim a língua nacional, ensinada na escola, preconizada como correta, pouco ou quase nada tem a ver com o modo como muitos brasileiros falam a língua. Os falantes da língua materna consideram-se incapazes de aprender LP e se dizem incompetentes inclusive como falantes, sentindo-se excluídos, externando assim o preconceito introjetado em sua memória.

Mariani (2004) apresenta de maneira contundente as marcas constitutivas da memória de nossa língua com a subserviência a Portugal, cuja origem se baseia na língua de colonização e que ainda hoje parece aprisionar o falante, para se firmar como língua nacional, tentando apagar outras marcas linguísticas, bem como sua heterogeneidade interna.

Seguindo estudos de Martins (2008), limitaremos esse trabalho à língua literária do século XIX, abrangendo apenas uma pequena camada dos falares de 1900, que impregnam as nossas gramáticas e culpabilizam o falante da variante não padrão da LP, condenando-o ao apagamento de sua vivência. 


\section{Panorama geral da história da língua portuguesa no Brasil do século XIX}

Só devemos interpretar o passado através do que há de mais forte no presente. (Nietzche)

A LP falada no Brasil do século XIX já apresentava traços distintivos da mesma na modalidade europeia. Não se tratava exatamente de confronto entre a língua portuguesa de Portugal e a língua portuguesa do Brasil, mas de um movimento de afirmação de uma identidade nacional que fez com que escritores românticos brasileiros se dispusessem a registrar em seus textos certos aspectos da variante brasileira.

Era importante então mostrar o caráter singular da construção da história da nossa língua, e através dele possibilitar a materialidade das marcas que nos caracterizam como indivíduo, como nação. Desse modo, estávamos nos deslocando do lugar tradicional destinado ao subserviente e nos levantando efetivamente como independentes, seja na política ou na linguística, marcava-se naquele momento uma ruptura com a língua portuguesa europeia.

No final do século XIX, com a burguesia em ascensão, a questão da língua nacional se colocava fortemente discutida para que a nação brasileira, recentemente independente de Portugal, progredisse no melhor sentido positivista da palavra. Tudo que não se adequasse a esse pensamento deveria ser curado ou eliminado do corpo social.

Mundi (2008) salienta que no século XVIII, em 1757, através do decreto chamado Diretório dos índios, iniciou-se o processo de institucionalização da LP como língua oficial do Brasil o que foi traumático, senão vejamos:

O ensino do português passou a ser feito autoritariamente por meio de compêndios gramaticais normativos que endemoninhavam tudo o que não fosse a norma culta falada e escrita em Portugal, estigmatizando todas as peculiaridades já gritantes do português brasileiro e condicionando o imaginário coletivo dos brasileiros a dar crédito apenas à norma culta portuguesa em detrimento de todas as outras variedades linguísticas existentes. (MUNDI, 2008)

Ora, ainda hoje, mesmo com os avanços latentes dos estudos linguísticos no Brasil, perduram nos livros didáticos exemplos cristalizados de registros formais da literatura do século XIX, como se fosse possível falar-se hoje nos mesmos moldes de trezentos anos, como se fosse possível dissociar a sócio-história do ensino da língua. 
O ensino da LP, obedecendo aos ditames únicos da gramática normativa e desprezando as variantes sem prestígio social, econômico ou geográfico, parece esquecer a influência preponderante da língua na construção do imaginário das pessoas; que a língua é um traço identitário que nos distingue, torna-nos únicos; e o pior, esquecer que somos pessoas livres e portadores de direitos, inclusive o de ser. Martins (2008) assevera como isso se dava:

A língua de cada escritor é uma fusão, em proporções variáveis, da língua aprendida no meio familiar e social e daquela que a escola e as leituras ministram. É essa combinação de língua transmitida e de língua adquirida que o artista molda em suas criações, imprimindo-lhe as marcas do seu talento e personalidade (MARTINS, 2008, p. 431)

Enfim é outra língua que se configura nesse outro espaço enunciativo: o brasileiro. Um espaço preenchido com marcas formais, adquiridas na escola, e outras informais e mais profundas, adquiridas no seio da convivência. Orlandi (1998), por exemplo, salienta que a língua é referência de identidade brasileira:

Podemos referir aqui a questão da língua nacional no Brasil como um dos elementos de definição da identidade brasileira. Esta questão leva à consideração da variação (e por aí da diversidade) na medida em que ela pode caracterizar o Brasil como um país distinto de Portugal. Mas, por outro lado, isto se inscreve na constituição da unidade necessária (ou de uma nova unidade) nesse novo espaço que é o Brasil. Assim, os indigenismos, os africanismos, os provincianismos, os regionalismos aparecem como diferenças "domesticadas", enquanto características do Brasil. (ORLANDI, 1998, p. 10)

É importante notar que a instituição da LP, tal como é possível perceber nas gramáticas normativas e no ensino tradicional da língua, é um traço forte da manobra político-ideológica para firmar e reafirmar o poder autoritário de nossos colonizadores e, mesmo em tempos atuais, o Português brasileiro, incipiente, é desprezado e taxado como variante de desprestígio, assim assegurado por Mariani (2004)

Ora, a imposição de uma língua única e nacional resulta da tentativa de aprisionamento do português brasileiro nas grades modelizantes da língua imaginária. É essa abstração 'língua portuguesa vinculada a uma memória de conquistas', que o século XIX majoritariamente nos lega, através das gramáticas e dicionários; dos diferentes tratados de unificação ortográfica e do ensino nas escolas. Ainda no século XIX, apesar das manifestações de independência, ao brasileiro ainda corresponde imaginariamente, pelo menos para aqueles que são filiados à memória portuguesa, um povo bárbaro e rústico das províncias que precisa continuar sendo conquistado e permanecer aprendendo a falar e a escrever corretamente o idioma nacional de Portugal. (MARIANI, 2004, p. 172-173) 
Os vários estratos que a LP possui são prova de sua riqueza e devem servir de elemento de agregação de valor, não de discriminação do falante; a real necessidade do alunado e do nosso país é a formação de um público-leitor com visão crítica e reflexiva sobre os vários tipos de textos que se nos apresentam. Manter abismos entre a língua ensinada nas escolas e a língua oral produzida pelo falante mantém o ciclo da diglossia ${ }^{1}$ e contribui cada vez mais para a discriminação negativa sofrida por quem não tem o poder de tornar a sua "variante da língua" padrão.

Mariani (2004) afirma que no século XIX e com a independência do Brasil de Portugal que outras questões se colocam, sobretudo a discussão sobre os sentidos da língua nacional dos brasileiros. Mas seria apenas com a ampliação da literatura de autoria brasileira que o problema se agudizaria e se tornaria pauta entre os intelectuais da época, para comprovação de testemunho podemos citar um dos mais importantes expoentes de nossa literatura, José de Alencar:

Falei-lhe há pouco da excentricidade de certos aumentativos. Usa-se no Ceará um gracioso e especial diminutivo, que talvez seja empregado em outras províncias: mas com certeza se há de generalizar, apenas se vulgarize.

Não permite certamente a rotina eumológica aplicar o diminutivo ao verbo. Pois em minha província o povo teve a lembrança de sujeitar o particípio presente a esta fórmula gramatical. E criou de tal sorte uma expressão cheia de encanto.

A mãe diz do filho que acalentou ao colo: "Está dormindinho". Que riqueza de expressão nesta frase tão simples e concisa! O mimo e ternura do afeto materno. A delicadeza da criança e sutileza do seu sono de passarinho, até o receio de acordá-la com uma palavra menos doce; tudo aí está nesse diminutivo verbal.

Entretanto, meu ilustre colega, suponha que em algum romance eu empregasse aquele idiotismo a meu ver mais elegante do que muita roupa velha com que os puristas repimpam suas ideias.

Não faltariam, como de outras vezes tem acontecido, críticos de orelha, que depois de medido o livro pela sua bitola, escrevessem com importância magistral: "Este sujeito não sabe gramática". E têm razão; gramática para eles é a artinha que aprenderam na escola, ou por outra, uma meia dúzia de regras que se afogam nas exceções.

\footnotetext{
${ }_{1}^{1}$ Diglossia - foi cunhada pelo linguista grego loannis Psycharia, primeiramente em francês (diglossie), para designar a situação linguística na qual, em uma dada sociedade, duas línguas funcionalmente diferenciadas coexistem, sendo que o uso de uma ou de outra depende da situação comunicativa. pt.wikipedia.org.
} 


\section{FACULDADE DE FORMAÇÃO dE PROFESSORES}

Nós, os escritores nacionais, se quisermos ser entendidos do nosso povo, havendo de falar-lhe em sua língua, com os termos ou locuções que ele entende, e que lhe traduzem os usos e sentimentos.

Não é somente no vocabulário, mas também na sintaxe da língua, que o nosso povo exerce o seu inauferível direito de imprimir o cunho de sua individualidade, abrasileirando o instrumento das ideias. (ALENCAR, 1964)

Desde a independência, a questão do ensino da língua padrão é questão controvertida, já que é possível apontar aspectos pertinentes do emprego da língua metropolitana europeia, mas a necessidade de utilização da língua escrita e o real uso da gramática normativa trouxeram a discussão sobre os parâmetros de uma literatura que, de alguma forma, fora imposta pelo colonizador.

Havia-se de se afirmar a nação independente; e, ainda, a aceitação ou não da presença da heterogeneidade dos falares no Brasil, a literatura foi a porta necessária para isso, modestamente no início, conforme veremos a seguir:

Não obstante os protestos renovadores e anticlassicistas do Romantismo e inegáveis inovações no manuseio da língua, a reverência aos clássicos continuava viva. O próprio Alencar, ao defender-se das acusações que lhe faziam de incorreção e pretensão de criar uma língua brasileira, não deixava de recorrer a citações de autores clássicos, que afirmava ter estudado e conhecer muito bem; é certo, contudo, que por vezes se justificava declarando sua preferência pessoal por determinada construção ou vocábulo. (MARTINS, 2008)

Em suma, os processos histórico-linguísticos em que contraditoriamente foram formadas as diretrizes da norma padrão gramatical permanecem salientando a discriminação do falante e inferiorizando tudo que não é espelho, o diferente na língua falada no Brasil, que conforme Mariani (1994) configura-se principalmente em três regiões de significação: o primeiro, "é o da lei com suas indefinições; os outros dois lugares enunciativos referem-se ao de alguns filólogos, gramáticos e historiadores, e ao de literatos"; é sempre lembrado como marca de nossa inferioridade comparada à presença autoritária do colonizador em nosso imaginário literário.

\section{O projeto inovador da liberdade: uma literatura com falares brasileiros}

Quero me referir à definição da nossa literatura como eminentemente interessada. Não quero dizer que seja social, nem que deseje tomar partido ideologicamente. Mas apenas que é toda voltada, no intuito 
dos escritores ou na opinião dos críticos, para a construção duma cultura válida no país. Quem escreve, contribui e se inscreve num processo histórico de elaboração nacional. (Antonio Candido)

$\mathrm{O}$ que tentaremos afirmar neste capítulo é o projeto de literatura do século XIX como um dos mais importantes e produtivos marcos de independência no Brasil. Atuante em nossas letras literárias e críticas, Machado de Assis desempenhou papel importante no contexto político brasileiro, formando e transformando opiniões desde as primeiras décadas do século XIX.

Assis desempenharia um importante papel em nossa vida literáriocultural, vivenciando, por dentro, o contexto no qual se cristalizam as nossas ideias e elaborações artísticas e, consequentemente, criticando a forma de escrever nas gramáticas de sua época e indiretamente as atuais, como a seguir:

Entre os muitos méritos dos nossos livros nem sempre figura o da pureza da linguagem. Não é raro ver intercalados em bom estilo os solecismos da linguagem comum, defeito grave, a que se junta o da excessiva influência da língua francesa. Este ponto é objeto de divergência entre os nossos escritores. Divergência digo, porque, se alguns caem naqueles defeitos por ignorância ou preguiça, outros há que os adotam por princípio, ou antes por uma exageração de princípio.

Não há dúvida que as línguas se aumentam e alteram com o tempo e as necessidades dos usos e costume. Querer que a nossa pare no século de quinhentos, é um erro igual ao de afirmar que a sua transplantação para a América não lhe inseriu riquezas novas. A este respeito a influência do povo é decisiva. Há, portanto, certos modos de dizer locuções novas, que de força entram no domínio do estilo e ganham direito de cidade.

Mas se isto é um fato incontestável, e se é verdadeiro o princípio que dele se deduz não me parece aceitável a opinião que admite todas as alterações da linguagem, ainda aquelas que destroem as leis da sintaxe e a essencial pureza do idioma. A influência popular tem um limite: e o escritor não está obrigado a receber e dar curso a tudo o que o abuso. O capricho e a moda inventam e fazem correr. Pelo contrário ele exerce também uma grande parte de influência a este respeito. Depurando a linguagem do povo e aperfeiçoando-lhe a razão. (ASSIS, 1973) (grifos nossos)

Os processos de produção de sentidos e de criação literária foram norteadores de discussões acaloradas sobre o nome e a natureza da língua do Brasil. Seria uma língua autônoma, a expressão de um povo indepen- 


\section{FACULDADE DE FORMAÇÃO DE PROFESSORES}

dente ou teríamos a angústia da influência ${ }^{2}$, e, portanto, subserviência à norma portuguesa?

Estudar-lhes as formas mais apuradas da linguagem, desentranhar deles mil riquezas que à força de velhas se fazem novas, não me parece que se deva desprezar. Nem tudo tinham os antigos, nem tudo têm os modernos, com os haveres de uns e outros é que se enriquece o pecúlio comum (ASSIS, apud MARTINS 2008)

A defesa de uma unidade linguística como instrumento de agremiação e agregação nacional perpassaria, necessariamente, pelo culto à normatização linguística portuguesa. Sob essa ótica, alguns gramáticos passaram a descrever a língua numa perspectiva estática, no espaço da memória portuguesa, como se a influência própria do povo não fosse decisiva para a mudança da língua, como se fosse possível ainda em nossos dias o falar de mil e quinhentos, conforme mostrado nas citações de Assis (1973).

Valorizando o imaginário popular, os autores românticos tornam a palavra, antes oral e espontânea, em matriz do texto escrito. Com essa sacralização da oralidade, Alencar sofre várias críticas por valorizar os falares brasileiros em suas obras conforme foi salientado por Madeira (2008):

O defeito que eu vejo nessa lenda (Iracema), o defeito que vejo em todos os livros brasileiros, e contra o qual não cessarei de bradar intrepidamente, é a falta de correção na linguagem portuguesa, ou antes, a mania de tornar o brasileiro uma língua diferente do velho português, por meio de neologismos arrojados e injustificáveis, e de insubordinações gramaticais que (tenham cautela!) chegarão a ser risíveis se quiserem tomar as proporções de uma insurreição [...] Nós cingimo-nos às velhas regras, nós sem nos desviarmos da linha reta, enquanto os brasileiros se comprazem em seguir umas veredas escabrosas, por onde caminha aos tombos a língua de Camões. (Apud CUNHA, 1994, p. 15)

Ou ainda:

Entendo, e creio que toda a gente, de senso, que, quando somos forçados a isto (ou seja, a inovar), importa saber a fundo a língua, tê-la estudado com espírito assaz esclarecido, como o fizeram Felinto, Fr. Francisco de S. Luís, Garrett, e Odorico Mendes, e ainda hoje assim o praticam os Srs. Visconde de Castilho, Alexandre Herculano e Latino Coelho. [...] Sem termos os conhecimentos indispensáveis e muita lição dos bons clássicos portugueses, que, pois, somos descendentes de Portugal e falamos a mesma língua, é loucura tentar

\footnotetext{
2 O livro Angústia da Influência de Harold Bloom é de extrema importância por tratar de pensar as relações entre obras e mesmo entre estilos, não só em termos necessários da contribuição dos clássicos em obras novas ou inovadoras, mas em termos de confronto, de combate criativo no qual o autor posterior realiza em obra uma resposta ao seu antecessor influente. Deslocamos o sentido da expressão por acreditarmos que a dependência linguística também gera uma certa "angústia" ao adquirente.
} 
empresas tais, que só servem para o descrédito de quem o faz. Deixemo-nos de inovações extravagantes, onde já é miséria, e grande, não sabermos usar das riquezas que herdamos, para melhor recorrermos e admitir tudo o de que precisamos a fim de exprimir coisas, ou novas, ou inteiramente brasileiras. [...] É pena que talento tão superior não se aplique ao estudo da língua, com mais interesse e sem prevenções. Porém, quanto a sua linguagem e estilo, são descuidados e por vezes desiguais e frouxos. (ibidem, p. 14-15)

A questão da língua é, assim, o foco de todo o pensamento e de toda a ação cívica dos críticos puristas do século XIX como se a instrução escolar, a integração nacional fossem papel civilizador e o culto da forma fosse necessário à integridade do Brasil como nação independente. Ao contrário, Alencar acreditava que a valorização da língua tipicamente brasileira convergiria para a afirmação do papel fundamental da sobrevivência do país republicano.

José de Alencar gozava de conceito social e político e em seus textos a abordava a estética linguística, valorizando os falares regionais. No trecho abaixo nota-se a estreita semelhança arcaica em face do desprendimento colonial lusitano:

- Abrenuntio! Abrenuntio!...Cruzes! Te esconjuro!

- O que é, Comadre? Perguntou-lhe a vizinha.

- O porco sujo que me está fossando na porta, senhora.

- T'arrenego! (ALENCAR, 1968)

Atualmente, por exemplo, a palavra Arrenego escrita na última frase do diálogo é escrita sem a vogal $a$, desinência desnecessária hoje tanto na norma padrão quanto no português coloquial. $O$ Garatuja foi a primeira de uma série de crônicas dos tempos coloniais, em que o autor, prazerosamente descumpria-se da formalidade emergente e vagueava na ocasionalidade popular.

O que os puristas pareciam e parecem não levar em conta é que uma nação independente precisa de autonomia, inclusive linguística, para realçar as especificidades de seu povo.

Quase um século depois, Bilac, outro conservador da língua de Camões, salientava o que acreditava ser a chave de seu conservadorismo, mas que na verdade poder-se-ia dizer ser o real problema por traz do purismo:

(...) afinal, o que constituiria esta nação? O que faz de nós um conjunto orgânico? Sem fundo étnico comum, sem um mesmo ritmo de progressão e- 


\section{FACULDADE DE FORMAÇÃO DE PROFESSORES}

conômica, sem homogênea distribuição das cidades e das riquezas, o que restava, além da inércia e do costume? A língua. (BILAC, 1924)

A coragem de Alencar em seu projeto inovador de literatura recebeu críticas profundas, especificamente ao tratamento que o autor deu à língua como expressão de seu povo.

O que parecia pretender Alencar era flexibilizar a escrita, aproximando-a da realidade falada no Brasil, legitimando termos tipicamente brasileiros em sua realidade expressiva no cotidiano e utilizando uma sintaxe menos subordinada aos paradigmas do português de Portugal.

Assim como Alencar, outros autores ousaram literalizar expressões de variações desprestigiadas na época e ainda hoje, como é o caso de Azevedo (2007):

(...) A criadagem da família, do Miranda compunha-se de Isaura, mulata ainda moça, moleirona e tola...uma negrinha virgem chamada Leonor, muito ligeira e viva, lisa e seca como um loque, conhecendo de orelha, sem lhe faltar um termo, a vasta tecnologia da obscenidade, e dizendo, sempre que os caixeiros ou os fregueses da taverna, só para mexer com ela, lhe davam atracações: Óia, que eu me queixo ao juiz de orfe (...) (AZEVEDO, 2004)

Madeira (2008) nos mostra que as observações negativas à literatura alencariana não partiam somente de Portugal, mas também de nacionalistas brasileiros, constantemente refutados por Alencar, conforme citações em seu artigo transcritas abaixo:

Uns certos profundíssimos filólogos negam-nos a nós brasileiros, o direito de legislar sobre a língua que falamos. [...] Nós, os escritores nacionais, se quisermos ser entendidos de nosso povo, havemos de falar-lhe em sua língua, com os termos e locuções que ele entende, e que lhes traduz os usos e sentimentos. Não é somente no vocabulário, mas também na sintaxe da língua, que o nosso povo exerce o seu inauferível direito de imprimir o cunho de sua individualidade, abrasileirando o instrumento das ideias. (Apud CUNHA, 1994, p. 24)

Se o português, transferindo-se para a América, desenvolvendo-se no seio de uma natureza tão opulenta, não tivesse o viço e a seiva necessários para brotar de si um novo idioma sonoro, exuberante e vigoroso, triste dele; seria uma língua exausta, votada a breve e rápida extinção (Ibidem, p. 42).

As críticas descontextualizadas do cenário social agiam em nome de uma aproximação com o ideal europeu que seria atingido por meio do exemplo, do objetivismo, da artificialidade da linguagem, do preciosismo etc. Madeira (2008) assim nos assevera:

Criticava-se a escola romântica, não só no que dizia respeito à temática, mas principalmente em função de suas incorreções gramaticais. (...) 
Obcecado pela forma, Rui Barbosa se destacava por seu estilo enfático e rebuscado, repleto de palavras e construções arcaicas. Dotado de incomum cultura linguística, defendia o rigor das regras gramaticais lusitanas, em oposição às concessões feitas por autores como Alencar e Castro Alves em favor de uma maior autenticidade expressiva nacional. (Apud CUNHA, 1994, p. 34)

Ainda segundo Madeira (2008),

Existe preocupação de se colocar em pauta a necessária discussão sobre as divergências verificadas entre a língua real, efetivamente utilizada, e a língua ideal, entidade abstrata preconizada pela norma-padrão (...).

Podemos afirmar que a língua, como atividade humana e social, é viva e é impossível evitar que, para se adaptar à sociedade, ela varie e mude com o passar do tempo. Os brasileiros passavam a viver sob uma marca cultural de autenticidade forte, totalmente diferente das gerações anteriores. Talvez por isso o aprendizado da língua portuguesa fosse tão desinteressante e talvez por isso ainda o seja.

(...) Cada sistema cultural está sempre em mudança. Entender esta dinâmica é importante para atenuar o choque entre as gerações e evitar comportamentos preconceituosos. Da mesma forma que é fundamental para a humanidade a compreensão das diferenças ente povos de culturas diferentes, é necessário saber entender as diferenças que ocorrem dentro do mesmo sistema (...) (LARAIA, 2006).

Ao nos referirmos ao ensino de LP fica difícil fazê-lo sem nos reportarmos à influência que o purismo ainda exerce na rotina das propostas educacionais. Os transtornos sociais pelos quais os alunos são submetidos, as especificidades geográficas, entre outras, são ignorados pelos professores normativos e suas práticas apontam para o preconceito linguístico como consequência de uma postura rígida de valores ainda tecidos sobre o dogma europeu.

O nosso país orgulha-se de sua condição de nação democrata, de povo acolhedor e respeitador das diferenças, mas é na língua que demonstramos a nossa mais recôndita e perversa faceta: o preconceito linguístico. Em nome dele, falantes nativos da LP sentem-se envergonhados de se expressarem em público e são automaticamente recolhidos à insignificância dos excluídos socialmente.

O preconceito, em qualquer de suas formas, principalmente o linguístico, deveria ser crime, porque tacitamente deprecia e desvaloriza o falante, desnudando-o, ridicularizando-o e negando a ele sua própria identidade, consequentemente, sua existência perante o outro. Alencar sabia disso e, aos poucos, foi privilegiando a princípio a figura feminina, 
também legada ao silêncio, e posteriormente, a figura do típico brasileiro, até hoje discriminalizado.

No Brasil, seguindo normas de direito internacional, a mulher é protegida pela lei 11340/06, o preconceito racial é expressamente proibido pela Constituição Federal em seu artigo $5^{\circ}$, XLII, contudo, a única normatização a respeito da língua, a gramática, é justamente discriminatória e castradora e, em vez de proteger o falante, acaba por leva-lo à condição de inferior.

(...) O modo de ver o mundo, as apreciações de ordem moral e valorativa, os diferences comportamentos sociais e mesmos as posturas são assim produtos de uma herança cultural, ou seja, o resultado da operação de uma determinada cultura (...) (LARAIA, 2006).

No entanto, todo falante nasce com o que se poderia chamar de gramática universal, justificando assim a facilidade com que a criança consegue reconhecer as regras e criar enunciados compreensíveis em diversas situações comunicativas ainda que não tenha tido qualquer contato com a escolarização formal.

A linguagem, que não tem somente a função de comunicar, revela a posição do falante na sociedade, deixando mais claras as situações de poder existentes, além de ter estreita relação com os níveis de letramento adquiridos pelo indivíduo.

Bagno (2006) sinaliza que a língua é muitas vezes um poderoso instrumento de ocultação da verdade, de manipulação do outro, de controle, de intimidação. Segundo o autor "a palavra não é neutra" e esse preconceito exercido sobre as pessoas mais estigmatizadas da sociedade como o analfabeto, o pobre, o nordestino, o sem escolaridade etc.

Os PCN - Parâmetros Curriculares Nacionais de Língua Portuguesa, assim como os de temas transversais, reconhecem a existência de variantes linguísticas, lembrando que não há um modo certo ou um modo errado de falar, contudo o preconceito se perpetua todos os dias nas escolas e fora delas através de atitudes levianas que levam milhares de pessoas, todos os dias, ao apagamento de seus registros falados ou ao relevo deles, para provocar riso.

É necessário perguntar até quando os professores estaremos dispostos a corroborar com tamanha violência, até quando seremos instrumento de perpetuação da escravidão moderna. Cabe-nos ao menos a denúncia, tal qual vai nesse trabalho. 


\section{Considerações finais}

O olhar que só reflete é espelho, mas o olhar que sonda e perscruta é foco de luz. O olhar não decalca passivamente, mas escolhe, recorta e julga as figuras da cena social mediante critérios que são culturais e morais, saturado, portanto de memória e pensamento. (Alfredo Bosi)

Diante do que se chamam "desvios" da norma considerada padrão, seria possível para os homens de letras da época de XIX, inclusive José de Alencar, afirmar que no Brasil independente havia outra forma linguística sobre a qual se poderia dizer que era uma língua de cultura e de civilização, em vez disso, quase todos se calaram diante da violência da padronização e do preconceito.

O papel do professor de língua portuguesa é o de contribuir para o fim do da marginalização da língua. Ainda que seja lenta e trabalhosa, será necessária uma conscientização sobre os mecanismos da língua falada em relação à cristalização, a estatização da língua escrita. Não propomos que se deixe de ensinar a língua padrão, mas que não se menospreze as outras variantes, legitimamente brasileiras, da língua.

Em nossa trajetória escolar, percebemos que o ensino da língua é algumas vezes ignorado no que envolve a significação, trazendo-se em relevo à gramática, corroborando para que o ensino se dê quase que exclusivamente mediante "regras" de "padrões gramaticais", enquanto que o trabalho reflexivo dos sujeitos, suas vivências e da variação linguística é desprezado.

Não propormos também vivenciar o drama da subserviência linguística, como se ainda não tivéssemos condição de nos libertar das amarras, há tanto rompidas, com nossos colonizadores, mas explicar que o preconceito destrói aos poucos um discurso democrático de que somos todos iguais na mesma configuração ambivalente de ser multicultural. Essa é nossa função como educadores e dela não podemos nos furtar.

Por vários aspectos, foi possível perceber que ainda estamos distantes de assegurarmos aulas sem preconceito de várias espécies, inclusive o linguístico, contudo, o conhecimento do assunto corrobora para a finalização do processo de subserviência aos padrões europeus de língua, aceitando e respeitando as diferenças que nos tornam plurais. 


\section{FACULDADE DE FORMAÇÃO DE PROFESSORES}

\section{REFERÊNCIAS BIBLIOGRÁFICAS}

ALENCAR, J. Posfácio de Iracema. In: ALENCAR, J. Obras completas, vol. 4. Rio de Janeiro: J. Aguilar, 1964, p. 965-966.

O garatuja. São Paulo: Saraiva, 1968

ASSIS, M. Instinto de nacionalidade. In: ASSIS, M. Obras Completas, vol. 3. Rio de Janeiro: Nova Aguilar, 1973, p. 808-809.

AZEVEDO, A. T. G. O cortiço. São Paulo: Martin Claret, 2004.

BAGNO, M. Preconceito linguístico: o que é, como se faz. 40. ed. São Paulo: Edições Loyola, 2006.

BILAC, O. Sobre a minha geração literária. In: Últimas conferências $e$ discursos. São Paulo: Francisco Alves, 1924, p. 79.

CUNHA, C. Língua portuguesa e realidade brasileira. 10. ed. Rio de Janeiro: Tempo Brasileiro, 1994.

LARAIA, R. B. Cultura, um conceito antropológico. Rio de Janeiro: Jorge Zahar, 2006.

MADEIRA, C. E. L. Nos meandros da linguagem: literatura e gramática. Inter Letras: Revista Transdisciplinar de Letras, Educação e Cultura da UNIGRAN, Dourados, MS, v. 2, n. 8, p.1-16, 01 ago. 2008. Disponível em: < http://www.unigran.br/revistas/interletras/ed_anteriores/n8/ > . Acesso em: 01 mar. 2011

MARIANI, B. Colonização linguística; línguas, política e religião (Brasil, sécs. XVI a XIX e Estados Unidos da América, século XVIII). Campinas: Pontes, 2004.

MARTINS, N.S. Século XIX: Notações histórico-teórica: A língua literária do século XIX. In: SPINA, S. História da língua portuguesa. Cotia: Ateliê Editorial, 2008, p. 427-483.

MATTOS E SILVA, R. V. Da sócio-história do português brasileiro para o ensino do português no Brasil hoje. In: AZEREDO, J. C. (Org.). Lingua portuguesa em debate: Conhecimento e ensino. 3. ed. Petrópolis: Vozes, 2002, p. 19-33.

MUNDI, B. Breve histórico do ensino de língua portuguesa do Brasil. Disponível em: http://enedius.blogspot.com/2008/10/histria-da-lingstica.html. Acesso em: 01 mar. 2011.

ORLANDI, E. P. Ética e política linguística, línguas e instrumentos linguísticos. Campinas: Pontes, 1998. 